\title{
The Science and Technology Parks (STPs) Evaluation Model Approach to Eco-Innovation Key Indicator
}

\author{
Mahdi Yami ${ }^{1}$, Gao Changchun ${ }^{2}$, Gao $\mathrm{Han}^{3}$ \\ ${ }^{1,2}$ School of Business and Management, Donghua University, Shanghai, China \\ ${ }^{3}$ School of Government, Peking University, Beijing, China \\ Correspondence: Mahdi Yami, No. 1218, 7e Ave, Montreal, QC., H1B 4J6, Canada.
}

Received: September 21, 2018

Accepted: October 22, 2018

Online Published: October 26, 2018

doi:10.5539/ibr.v11n11p187

URL: https://doi.org/10.5539/ibr.v11n11p187

\begin{abstract}
Science and Technology Park (STP) is one of the most important innovation policies to develop the regional economy. To manage the STPs successfully, a standard evaluation system as a reference is needed. However, there is no consensus about the definition of successful STPs due to their different goals and regions. Hence, it is necessary to establish a reference framework to evaluate the success of different STPs and it is essential to assess their main goals as the competitive advantage by a set of innovation indicators. This study developed a research model to evaluate the competitiveness of STPs by analyzing the impact of innovation subjective externalities based on the Global Innovation Index (GII) and approach to the eco-innovation key indicator. This STP evaluation model is adopted and tested by two different fuzzy analyzing and examines the survey forms and questionnaires that have been filled by some STP experts and as a case study all the evidence has been gathered and analyzed from "Caohejing Hi-Tech Park" in Shanghai and the results evaluated the competitive advantage via innovation policies and performances and the rating rank contents some innovation main dimensions, key indicators and factors and also the important result as eco-innovation development and diffusion.
\end{abstract}

Keywords: science and technology park, innovation evaluation, eco-innovation, competitive advantage, fuzzy, global innovation index, diffusion

\section{Introduction}

The Science and Technology Park (STP), is a powerful complex to develop the regional innovation to be set up as a techno-polis.(Wikipedia, n.d.-b) In recent years a good number of researches involved in evaluating the STPs to find the best way willing to compare different STPs structures. But as a consequence, many factors extend on a large set of dimensions affecting the STPs and this feature makes STPs particularly difficult to be properly evaluated or compared. Hence, a standard STP evaluation index is extremely needed to cover the entire subjects in policies and performances.(Ferrara, Lamperti, \& Mavilia, 2016)

The innovation is the main indicator of the STP evaluation to cover and promote many other factors.(Diez-Vial \& Montoro-Sanchez, 2016) Measuring innovation outcome is a powerful dimension for STPs to evaluate the capabilities.(Zeng, Xie, \& Tam, 2010) However, the most important characteristic of the innovation outcome measurement approach is eco-innovation development.(Specht, Zoll, \& Siebert, 2016) Hence, a reference framework system is deeply necessary to measure the innovation outcome related to eco-innovation development result.

This research aims to capture a multi-dimensional evaluation model by discussing the nature of STP according to the innovation measurement. This innovation large scale, based on global innovation index (GII) is obtained to evaluate the effectiveness both of the innovation policies and innovation performances. This model as a comprehensive framework measures the innovation input to output growth upon improving the eco-innovation development as a strong competitive advantage. The feedbacks of an STP in Shanghai - China as the case study considered the effectiveness of innovation output on STPs competitiveness.

In recent years many pieces of research tried to illustrate the STP evaluation methods, also there are some STP evaluation handbooks encouraged by governmental commissions (e.g. European Commissions1, OECD2, etc.)

${ }^{1}$ www.ec.europa.eu 
but following this kind of paper-based methods would take so much time, cost and administrative affairs. Some other traditional STP evaluation methods just redefine the limited definitions without proposing a practical model of evaluation. We are trying to illustrate a practical index with the prompt method and also accurate result in measuring the outcome key dimensions as the key goals. This index is a multi-level dynamic system, involving various indicators to follow the objectivity systematic principles.(Xu, Wang, \& Wang, 2011)

In section 2 (Literature Review), we follow the introduction by literature review to discuss and dominate the previously published papers and survey the precedent attempts at STPs evaluation. In section 3, as the methodology and measurement tools, the main dimensions and comprehensive subjects for STP evaluation is considered. In section 4, the experimental result of the surveys and questionnaires will explain. In section 5 , as the Discussion, is the main part of our research model to analyze the result and compare with other scholars. In section 6 , concludes the research and we finally signed the paper by section 7 as the references.

\section{Literature Review}

\subsection{Background}

"Science and Technology Parks" (STPs) play important role in creating the innovation to grow the competitive advantages. STPs are designed to offer a number of shared services, utility, and product resources, such as incubators and collaboration facilities to industrial and research plants(Kolahi, 2015) to add value, reduce costs, improve the environment, and achieve innovation sustainable development.(Wu, Wang, Hong, Piperopoulos, \& Zhuo, 2016) The convergence of policies, performances, and facilities play a key role in the STPs for facilitating the communication, knowledge flow, new businesses creation and internationalization.(IASP, n.d.) The "International Association of Science Parks"3 and "Association of University Research Parks"4 are two main associations related to the STPs.

In many scholars, the literature on STPs has the title of "Regional Innovation System" due to regional input to output characterized by cooperative innovation.(Tsai \& Chang, 2016) This cooperation and interaction in STPs is emphasized because internal innovation also needs to obtain from universities and other regional firms and it is highly concentrated on competitive regions to the positive impact the competitiveness.(D. Minguillo, Tijssen, \& Thelwall, 2015) The STPs innovation strategies as knowledge and information technology enhance the competitive advantages.(Yang \& Ying, 2015) The potential of competitive advantage of locating in STPs increases due to outcome benefits and innovation circulation development.(Ruiz-Ortega, Parra-Requena, \& Garcia-Villaverde, 2016) As a result, the innovation outcome in the STPs is a positive impact on competitive advantage,(D. Minguillo et al., 2015) and the eco-innovation development is a high factor in innovation outcome.(Kbar \& Aly, 2015)

\subsection{The main Dimensions that Affect the STPs}

It is necessary to establish a multi-criterion evaluation system as a reference framework to compare the effectiveness of dimensions to the STPs.(Drawoska, 2011) The most prominent scholars show that some dimensions have been determined such as Policies, labor markets environment benefits, the availability of network infrastructure, business start-up rate and market, entrepreneurial knowledge and $R \& D$ and finally the innovation(Alvarez, 2014) that are main effective dimensions on the potential of creating competitive advantages in STPs. These dimensions can improve all other dimensions of STPs and help to increase the total result of innovation.(Aliahmadi, Sadeghi, Nozari, Jafari-Eskandari, \& Najafi, 2015)

But some existing literature reveals considering the arguments lead us to the innovation output and lack of a clear evaluation of STPs makes difficult to understand their innovative output.(Liberati, Marinucci, \& Tanzi, 2015) One of the main important indicators in innovation output is the eco-innovation and regard to common innovation benefits defined through identified criteria to evaluate.(Stosic, Milutinovic, Zakic, \& Zivkovic, 2016)

1) Policies: The innovation policies from regional government initiated the innovation without central or regional government's support(Yim, Cho, \& Kim, 2015) to shift orientation the regional public and social advantages.(Clark, 2014) To strengthen the efforts of policies is by the innovation evaluation system to raise the innovation motivations.(Liu \& Guan, 2016) A good and perfect evaluation model is to cover the policy innovation to mix with the performances and make a tool to measure the STPs innovation.(Jordan \& Huitema, 2014)

\footnotetext{
${ }^{2}$ Www.oecd.org

${ }^{3}$ www.iasp.ws

${ }^{4}$ www.aurp.net
} 
2) Human Resource: Regarding human capital theory, human resource quality is adapted to regional innovation strategy.(Li, Qin, Jiang, Zhang, \& Gao, 2015) The rapid development of innovation should focus on social benefits, job creation and human resource management.(Donate \& Guadamillas, 2015) The human resource also is beneficial to strengthening the advantage of regional innovation.(Chang, Tsai, \& Henderson, 2012) Human resource affection measures to examine the STP location decision. The firms enjoy stronger employment growth in university STPs.(Wright, Liu, Buck, \& Filatotchev, 2008)

3) Network: The STPs are the network-based complex enhance the global innovation by network(Rycroft, 2007) and relationship increases the innovation by infrastructures and network promotion(Vasquez-Urriago, Barge-Gil, \& Rico, 2016a) to diffuse knowledge on a reciprocal basis.(Díez-Vial \& Fernández-Olmos, 2015) The knowledge obtained from universities by network will make innovation carried out by firms located in the STPs especially that firms located in central positions of the local firm-network like an intermediate brokerage in the innovation flows.(Diez-Vial \& Montoro-Sanchez, 2016) The STPs structured innovation network, promote the creation of new businesses and internationalization.(Wu et al., 2016)

4) Market: STPs are as a bridge between innovation strategy and market value. The marketing issue, sales growth, and profitability are more in STP than off-park firms.(Löfsten \& Lindelöf, 2002) The product-based firms linked to STPs know that the business network value is rather than single activities.(Corsaro, Ramos, Henneberg, \& Naudé, 2012) STPs are the results of the marketization and commercialization by innovative activities,(Zou \& Zhao, 2014) foreign investment(Zhang \& Sonobe, 2011) creation and global markets.(Liberati et al., 2015) In the STPs the innovation partners acquire new ideas to create a new competitiveness advantage(Chen, Chen, \& Lan, 2016) to add value through product innovation in the market.(Nishitani \& Itoh, 2016)

5) Knowledge: STPs promote knowledge activities as Research and development (R\&D), Research and technology (R\&T) and researching results commercialization.(Chun, Chung, \& Bang, 2015) The knowledge investment in the STPs increase the positive impact of regional R\&D collaboration, patenting and innovation factors(David Minguillo \& Thelwall, 2015). The R\&D cooperation between industries and universities are rather than research institutes. A knowledge base STP is following the goal of knowledge commercialization as the output.(Jongwanich, Kohpaiboon, \& Yang, 2014)

\subsection{Innovation Evaluation}

For measuring the innovation, the most important step is to measure the regional innovation cooperation(Avermaete et al., 2003) and efficacy of innovations to identify strengths and weaknesses in functions(Mahroum \& Alsaleh, 2012) It also defines the intended results of the innovation-based strategic objective as quality, quantity, efficiency and success.(Stosic et al., 2016) During the innovation process, a new change in regional innovation output to eco-innovation as a new behavior and culture has an important position.(Tsai \& Chang, 2016)

\subsubsection{Innovation}

Locate in an STP promotes innovation,(Vasquez-Urriago, Barge-Gil, \& Rico, 2016b) so in order to path for the STPs, we should consider the policy and the performance evaluation index system from several aspects such as innovative resources input, innovative cooperation process, and output.(Jiang, 2015) Firms without innovation efforts do not benefit from a park location. To achieve a high innovation return from STPs should measure the output, enhance the culture of innovation diffusion and also increase the intangible benefits of innovation flow(Vasquez-Urriago et al., 2016b) due mainly to a more diverse flow(Vasquez-Urriago et al., 2016a) and to guide the formers, investors and policymakers.(Formica, 2009)

\subsubsection{Eco-Innovation}

The most important result of innovation output is to create social profit value and eco-innovation as the competitive advantage.(Herrera, 2015) Social benefits are covered by new products, processes, and services to lead the business and innovation together to create job, stability, and also reduce the overall negative impact on the environment.(Stosic et al., 2016) Eco-innovation is a social innovative output toward new "ecological" ideas to contribute the sustainable developments(Wikipedia, n.d.-a) and share the strong knowledge-based economy and latest technologies. Hence, a proper eco-system plays an important role in creating innovation by identifying the real value of innovation to achieve the STPs optimal goal achievement.(Kbar \& Aly, 2015) Eco-innovation development should be in direction of eco-innovation diffusion.(Karakaya, Hidalgo, \& Nuur, 2014) Socio-economic outcomes of eco-innovation has main effects of eco-innovation activities for society and the economy, that includes changes in employment, turnover by export of products from eco-industries, circular economy and employment. (See Note 1) 


\subsubsection{The Global Innovation Index (GII)}

One of the challenges in the multi-dimensional innovation assessment is the innovation development(Stosic et al., 2016) to emphasize competitiveness (Martinsuo \& Poskela, 2011) and to cover goals beyond the innovation output. (Gamal, Salah, \& Elrayyes, 2011) Porter in 1990 noted that the STPs are different because the difference of some policies or performances in the nations(Sadeghi \& Sadabadi, 2015) so, not only an index to compare the STPs in a country, but also we need a new index which is amenable to global comparisons.(Manrique \& Velásquez, 2011)

The Global Innovation Index (GII) is an annual ranking of 141 countries economy to compare their level of innovation derived from several sources to create a system in which innovation factors are continually evaluated. (WIPO, 2015) GII provides a multi-criteria tool and a rich database to promote long-term output growth.(GII, 2015) To measure the innovation the majority of methods are assessing just the performances without policies, but GII is a global ranking to compare countries by their level of success in innovation based on both policies and performances, input-output indicators and subjective-objective data. GII is suitable to evaluate the STPs in complex and wide countries (as like as China).

\subsection{The STPs in China}

From 1990 under the Torch program, China established and developed more than 80 STPs on 53 china's metropolises due to the concentration of high technology Small and Medium Enterprises (SMEs).(Hu, 2007) Shanghai as the most populous metropolis in China with more than 24 million population (2014) is a global business hub(Wikipedia, n.d.-c) with more than thirteen technology-industrial zones that two science-technology parks in this group are the biggest one as "Zhangjiang Hi-Tech Park" and "Caohejing Hi-Tech Park".

We had some interviews by the Zhangjiang Hi-Tech Park experts. This park specializes in research of life sciences, software, semiconductors, and information technology. In some circles, the park is also known as China's Silicon Valley.(Wikipedia, n.d.-d) This park with Caohejing Hi-Tech Park focuses on the development of information industry, new materials, environmental protection, new energy, and other industries, while the introduction of a high level of supporting services.(caohejing-Park, n.d.) The "Caohejing Hi-Tech Park in Shanghai" in China based on the literature, have been weighted by outcomes of the innovation by considering the total dimensions and effectiveness.

\section{Methodology and Measurement}

In every evaluation methodology, the appropriate choice of measurement will depend upon the scorecard framework based on the impact of main dimensions and the key indicators.(Perrin, 2002) Regarding the previous studies, the best method to evaluate the STP is to prepare a multi-criteria innovation index as an evaluation framework. Our new model is including some innovation metrics, investigating innovation indices, dimensions different innovation indicators and factors to consider this idea. Our method offers an effective way of research by administered surveys and interviews (face-to-face) as follows:

\subsection{The Initial Interviews (First Step)}

At first the three science parks of "ZhongGuanCun Science Park" in Beijing, "Zhangjiang Hi-Tech Park" and "Caohejing Hi-Tech Park" in Shanghai was selected to do some initial interviews refer to related experts who are: The administrative committee of "ZhongGuanCun Science Park" in Beijing, Business development center of "Zhangjiang Hi-Tech Park" and project supervisor in "Caohejing Hi-Tech Park" in Shanghai.

In all interviews five categories determined as the main influencing dimension to innovation in the STPs: Policies, Human Resources, Network, Market and knowledge. However, many innovation evaluation indices (See Note 2) was studied to find the innovation outcome factors to follow the goal of eco-system in the STPs and Global Innovation Index (GII) ${ }^{5}$.

The entire dimensions have been prepared based on GII innovation scopes due to a fruitful development perspective by innovation input and output. However, some weakness of GII includes indicators that go beyond the traditional measures of innovation (GII, 2015) and also it cannot make a strong relationship among indicators representing input and output.(Sohn, Kim, \& Jeon, 2016) Hence, we have decided to add "eco-innovation development" in the output as one of the main new STP goals of eco-system and also make a strong chain between innovation input and output by fuzzy AHP process and DEA process.

\footnotetext{
${ }^{5}$ www.globalinnovationindex.org
} 


\subsection{The Surveys (Second Step)}

We prepared a questionnaire presented two main groups of studies composed of our case study. The first group investigates the ranking and determines the seven key dimensions in the STPs according to GII scopes. The second group insists on new innovation output indicator as eco-innovation development. Upon the feedback also the question reports and forms finished with asking their views, weakness or advantage of our evaluation index. The surveys sent to the abovementioned experts of the three parks who had interviewed before. After their modification proposals, the approved result of the dimensions is shown in Table 2 (in Results), and the key indicators of STPs organized as shown in Table 3 (in Results), as the criterion index.

Table 1. The evaluative scales

\begin{tabular}{ll}
\hline AHP Scale affection (9 points) \\
\hline Qualitative & Quantitative \\
variables & Value \\
No affect & 1 \\
Minor affect & 3 \\
Neutral & 5 \\
Moderate affect & 7 \\
Major affect & 9
\end{tabular}

\begin{tabular}{ll}
\hline Likert-Type scale affection (5 points) \\
\hline Qualitative & Quantitative \\
variables & Value \\
No affect & 0 \\
Minor affect & 0.5 \\
Neutral & 1 \\
Moderate affect & 1.5 \\
Major affect & 2 \\
\hline
\end{tabular}

\begin{tabular}{ll|}
\hline Parentage scale affection (5 points) \\
\hline Qualitative & Quantitative \\
variables & Value \\
No affect & $0<\mathrm{V} \leqq 20 \%$ \\
Minor affect & $20 \%<\mathrm{V} \leqq 40 \%$ \\
Neutral & $40 \%<\mathrm{V} \leqq 60 \%$ \\
Moderate affect & $60 \%<\mathrm{V} \leqq 80 \%$ \\
Major affect & $80 \%<\mathrm{V} \leqq 100 \%$
\end{tabular}

In Table 1, every qualitative variable evaluated by five-level response anchors $\mathrm{V}=(\mathrm{v} 1, \mathrm{v} 2$, v3, v4, v5) relative to affection with five points quantitative value and nine points for AHP scale. After finalizing the scorecard and the impact, the questionnaires sent to 10 experts in "Caohejing Hi-Tech Park" in order to define the affections. All the experts selected in the position of the CEO, HR manager, R\&D manager and etc.

\subsection{The Analysis (Third Step)}

After gathering hand-collected data of the questionnaires and also data were collected using semi-structured interviews, all the non-parametric statistical calculation has been analyzed to identify the weights and efficiencies of the STPs by MATLAB. Two different fuzzy methods as AHP and DEA are selected to separately make the framework for analyzing, modeling, and optimization the uncertainties.

The Analytic Hierarchy Process (AHP) is a structured technique for analyzing the best goal and understanding of the problems of the goals. It provides a rational framework to structure and quantify the elements and also to relate the elements to overall goals and alternatives. In addition, Data Envelopment Analysis (DEA) is the method of productive efficiency in operations management where a set of measures is selected relating multiple outputs to multiple inputs to be estimated. The AHP issued the weights of the efficiency of innovation inputs and outputs separately and then in another process of DEA we linked the innovation input indicators to the output goals. Finally, we concluded by comparing the results in two different methods.

\section{Results}

In "Caohejing Hi-Tech Park" from 10 questionnaires in total refers to the experts, 5 answered survey forms actual gathered of which three were valid as the statistical society. (The most problem is that all the experts are in high administrative position and not accessible).

Table 2. The main dimensions

\begin{tabular}{llll}
\hline A. & INNOVATION INPUT & B. & INNOVATION OUTPUT \\
\hline I1 & Policies & O1 & Knowledge \& tech outputs \\
I2 & Human Resource & O2 & Creative outputs \\
I3 & Network & O3 & Eco - Innovation Development \\
I4 & Market & & \\
I5 & Knowledge & & \\
\hline
\end{tabular}

In Table 2, The dimensions according to the replied questionnaires have constructed, and at the first survey, all the experts confirmed the "eco-innovation development" as a necessary goal. But in interviews, they insisted that this goal needs some infrastructures as green early stage investments and also environmental and energy R\&D outlays. They mentioned the result will available as Eco-innovation related patents, academic publications and media coverage in the science section. In the technology section, it will be available as Exports of products from eco-industries, circular economy. 
Table 3. Criterion, the key Indicators relative to the main dimensions

\begin{tabular}{|c|c|c|c|}
\hline Ii & $\begin{array}{l}1^{\text {st }} \text { Level, } \\
\text { Dimensions }\end{array}$ & $\mathrm{Ai}$ & $2^{\text {nd }}$ level - Indicators \\
\hline \multirow[t]{3}{*}{ I1 } & \multirow{3}{*}{$\begin{array}{l}\text { Institutions } \\
\text { (Policies) }\end{array}$} & $\mathrm{A} 1$ & Policy \\
\hline & & $\mathrm{A} 2$ & Laws \\
\hline & & A3 & Ease of Business \\
\hline \multirow[t]{3}{*}{$\mathrm{I} 2$} & \multirow{3}{*}{$\begin{array}{l}\text { Human } \\
\text { Resources }\end{array}$} & A4 & Education \\
\hline & & A5 & High Educated labors \\
\hline & & A6 & Employment policies \\
\hline \multirow[t]{3}{*}{ I3 } & \multirow[t]{3}{*}{ Infrastructure } & A7 & ICTs \\
\hline & & A8 & General Infrastructure \\
\hline & & A9 & Ecological Sustainability \\
\hline \multirow[t]{3}{*}{ I4 } & \multirow[t]{3}{*}{ Market } & A10 & Investment \\
\hline & & A11 & Credit \\
\hline & & A12 & Trade and Competition \\
\hline \multirow[t]{3}{*}{ I5 } & \multirow[t]{3}{*}{ Knowledge } & A13 & Knowledge Linkages \\
\hline & & A14 & Knowledge performance \\
\hline & & A15 & Knowledge Absorption \\
\hline
\end{tabular}

\begin{tabular}{|c|c|c|c|}
\hline Oi & $\begin{array}{l}1^{\text {st }} \text { Level, } \\
\text { Dimensions }\end{array}$ & $\mathrm{Bi}$ & $2^{\text {nd }}$ level - Indicators \\
\hline \multirow[t]{3}{*}{$\mathrm{O} 1$} & \multirow{3}{*}{$\begin{array}{l}\text { Knowledge and } \\
\text { technology } \\
\text { outputs }\end{array}$} & B1 & Knowledge Diffusion \\
\hline & & B2 & Knowledge Creation \\
\hline & & B3 & HR knowledge development \\
\hline \multirow[t]{3}{*}{$\mathrm{O} 2$} & \multirow[t]{3}{*}{ Creative outputs } & B4 & Intangible Assets \\
\hline & & B5 & Creation \\
\hline & & B6 & Online Creation \\
\hline \multirow[t]{3}{*}{$\mathrm{O} 3$} & \multirow{3}{*}{$\begin{array}{l}\text { Eco - Innovation } \\
\text { Development }\end{array}$} & B7 & Eco - social process \\
\hline & & B8 & Eco - Environment \\
\hline & & B9 & Eco - technological term \\
\hline
\end{tabular}

In Table 3, Regarding the GII and studies about the eco-innovation, all 24 indicators set the dimensions A1-A15 for innovation input, and B1-B9 for innovation output. Then a $24 \times 24$ matrix has prepared but in the first consideration, the experts pointed that this questionnaire (matrix) is huge and baffling (For example in O1 the B1, B2, and B3 are in the same goal group). Hence we ignored the output indicators because our main goal is considering the main output goals, not output indicators. So we constructed the frameworks as innovation input and innovation output separately, and analysis structured for inputs by indicators and for outputs by dimensions.

\subsection{Analysis by AHP Method}

According to the replies in questionnaires, after adjusting the data by AHP scale relative affection 1-9 points, the pairwise comparison matrix outcomes by equation (1). " $\mathrm{A}$ " is the alternatives based on $\mathrm{i}$ :

$$
\boldsymbol{A}_{\boldsymbol{A H P}}{ }^{i}=\sum_{j=1}^{n} a_{i j} w_{j}
$$

Table 4. AHP method for innovation outputs

$$
\left[\begin{array}{ccc}
1 & 1 / 2 & 1 / 4 \\
2 & 1 & 1 / 2 \\
4 & 2 & 1
\end{array}\right]
$$

\begin{tabular}{|c|c|c|c|c|}
\hline \multirow{4}{*}{$\begin{array}{l}\text { Pairwise } \\
\text { Comparison } \\
\text { Matrix }\end{array}$} & & $\mathrm{O} 1$ & $\mathrm{O} 2$ & O3 \\
\hline & $\mathrm{O} 1$ & 1.00 & 0.50 & 0.33 \\
\hline & $\mathrm{O} 2$ & 2.00 & 1.00 & 1.00 \\
\hline & $\mathrm{O} 3$ & 3.00 & 1.00 & 1.00 \\
\hline & Sum & 6.00 & 2.50 & 2.33 \\
\hline
\end{tabular}

\begin{tabular}{|c|c|c|c|c|c|c|c|c|}
\hline \multicolumn{9}{|c|}{ Standardized Matrix } \\
\hline & O1 & $\mathrm{O} 2$ & $\mathrm{O} 3$ & Total & Average & Weight & Cons. & Average \\
\hline $\mathrm{O} 1$ & 0.17 & 0.20 & 0.14 & 0.51 & 0.170 & $18 \%$ & 3.01 & $C=3.02$ \\
\hline $\mathrm{O} 2$ & 0.33 & 0.40 & 0.43 & 1.16 & 0.388 & $38 \%$ & 3.02 & $C I=0.01$ \\
\hline $\mathrm{O} 3$ & 0.50 & 0.40 & 0.43 & 1.33 & 0.443 & $44 \%$ & 3.03 & $R I=0.58$ \\
\hline Sum & 1.00 & 1.00 & 1.00 & 3.00 & 1.000 & $100 \%$ & & $C R=0.01578326$ \\
\hline \multicolumn{8}{|c|}{$\mathrm{CR}=0.01$ is True $(\mathrm{CR}<=0.1)$} & \\
\hline
\end{tabular}


In Table 4, according to the replies in questionnaires, after adjusting the data by AHP scale relative affection 1-9 points, the alternatives in terms of all criteria by equation (1) resulted in the weight of $\mathrm{O} 1$ is $18 \%, \mathrm{O} 2$ is $38 \%$ and $\mathrm{O} 3$ is $44 \%$.

$$
\kappa_{\text {max }}=\sum_{j=1}^{n} \frac{(S . V)}{n . w v_{j}}
$$

And:

$$
C I=\frac{\kappa_{\max }-n}{\mathrm{n}-1}
$$

The AHP method for innovation output is by $\mathrm{CR}$ as:

$$
C R=\frac{\mathrm{CI}}{\mathrm{RI}}
$$

In equation (2), "V" is the value of "i" $i$ "th output and " $j$ "th input. Regarding to "CI" equation (3), if the final value

\begin{tabular}{|c|c|c|c|c|c|c|c|c|c|c|c|}
\hline \multirow[b]{2}{*}{$\lceil 1$} & \multirow[b]{2}{*}{$1 / 9$} & \multirow[b]{2}{*}{$1 / 4$} & \multirow[b]{2}{*}{$1 / 7$} & \multirow[b]{2}{*}{$1 / 8$} & \multirow{5}{*}{$\begin{array}{l}\text { Pairwise } \\
\text { Comparison } \\
\text { Matrix }\end{array}$} & & I1 & I2 & I3 & I4 & I5 \\
\hline & & & & & & I1 & 1.00 & 0.11 & 0.25 & 0.14 & 0.13 \\
\hline 9 & 1 & 2 & 2 & 1 & & I2 & 9.00 & 1.00 & 2.00 & 2.00 & 1.00 \\
\hline 4 & $1 / 2$ & 1 & $1 / 2$ & $1 / 2$ & & I3 & 4.00 & 0.50 & 1.00 & 0.50 & 0.50 \\
\hline 7 & $1 / 2$ & 2 & 1 & 1 & & I4 & 7.00 & 0.50 & 2.00 & 1.00 & 1.00 \\
\hline 8 & 1 & 2 & 1 & 1 & & I5 & 8.00 & 1.00 & 2.00 & 1.00 & 1.00 \\
\hline & & & & & & Sum & 29.00 & 3.11 & 7.25 & 4.64 & 3.63 \\
\hline
\end{tabular}
of innovation output "CR" is no higher than 0.1, as equation (4) all the process is approved. (Saaty, 1980).

Table 5. AHP method for innovation inputs

\begin{tabular}{|l|l|l|l|l|l|r|r|r|r|l|}
\hline \multicolumn{10}{|c|}{ Standardized Matrix } \\
\hline & I1 & I2 & I3 & I4 & I5 & Total & Average & Weight & Consistancy & Average \\
\hline I1 & 0.03 & 0.04 & 0.03 & 0.03 & 0.03 & 0.17 & 0.034 & $\mathbf{3 \%}$ & 5.05 & C $=5.05$ \\
\hline I2 & 0.31 & 0.32 & 0.28 & 0.43 & 0.28 & 1.61 & 0.323 & $\mathbf{3 2 \%}$ & 5.09 & CI $=0.01$ \\
\hline I3 & 0.14 & 0.16 & 0.14 & 0.11 & 0.14 & 0.68 & 0.136 & $\mathbf{1 4 \%}$ & 5.04 & RI $=1.12$ \\
\hline I4 & 0.24 & 0.16 & 0.28 & 0.22 & 0.28 & 1.17 & 0.234 & $\mathbf{2 3 \%}$ & 5.04 & \\
\hline I5 & 0.28 & 0.32 & 0.28 & 0.22 & 0.28 & 1.36 & 0.273 & $\mathbf{2 8 \%}$ & 5.04 & \\
\hline Sum & 1.00 & 1.00 & 1.00 & 1.00 & 1.00 & 5.00 & 1.000 & $\mathbf{1 0 0 \%}$ & & CR $=0.01100954$ \\
\hline \multicolumn{10}{|c|}{ CR=0.01 is True (CR <=0.1) } \\
\hline
\end{tabular}

In table 5, in inputs separately condition, the same method and is tested by CR value. The data were normalized using the hybrid method of DEA. The affection weights matrix had set up by the values of questionnaires in finding the affection value of outputs on inputs.

\subsection{Analysis by DEA Method}

Data Envelopment Analysis (DEA) method is useful for weight restrictions conditions when judgement values are in the form of additional constraints on the input and output weights. These constraints reduce the flexibility of weights and improve the deviation in the DEA model. The optimum weight of the input-oriented multiplier in DEA method extends the same modification to the output-oriented model in terms of variable input and output weights (multipliers model). If all weight restrictions are separated the multiplier model correctly identifies the optimal weights. But, problem arises when at least one weight is linked. In this case the optimal weight is not in the best comparison. (Podinovski, 2016)

Hence, we should approach to separate the innovation input and output is possible because the first identified and the smooth surface are fitted.(Sreedevi, Vimala, Rameswari, Sateesh, \& Professor, 2016) But we should make a powerful link by the DEA fuzzy method to find the weight and affection of inputs to output as a strong bridge. 
If "V" is the value of "i"th output and " $\mathrm{j}$ "th input, " $\mathrm{W}$ " is the normalized weight and "O" is the optimum weight, Then:

$$
\text { Final } \mathrm{W}=\sum_{i=1}^{n} W_{i} \sum_{j=1}^{n} V_{i j} / O_{i j} / n
$$

The total weight of inputs and outputs calculated and adjusted by equation (5), the final $\mathrm{W}$ represents the optimum weight as the decision-making unit under the assessment.

Table 6. Ranking result by Optimization

\begin{tabular}{|c|c|c|c|c|c|c|c|c|c|c|c|c|c|c|c|c|c|}
\hline & \multicolumn{3}{|c|}{ I1 } & \multicolumn{3}{|c|}{ I2 } & \multicolumn{3}{|c|}{ I3 } & \multicolumn{3}{|c|}{ I4 } & \multicolumn{3}{|c|}{ I5 } & \multirow[t]{2}{*}{ Total } & \\
\hline & A1 & A2 & A3 & A4 & A5 & A6 & A7 & A8 & A9 & $\mathrm{A} 10$ & A11 & A12 & A13 & A14 & A15 & & \\
\hline O1 & 0 & 0.5 & 0.5 & 1.5 & 1 & 1 & 0.5 & 0.5 & 0 & 1 & 1 & 0.5 & 1 & 0.5 & 0.5 & 10 & 0.18 \\
\hline $\mathrm{O} 2$ & 0.5 & 1 & 1 & 2 & 2 & 2 & 1 & 1 & 0.5 & 2 & 1.5 & 1 & 2 & 2 & 1.5 & 21 & 0.38 \\
\hline $\mathrm{O} 3$ & 1 & 1 & 1 & 2 & 2 & 2 & 1.5 & 1.5 & 1.5 & 2 & 1.5 & 1 & 2 & 2 & 1.5 & 23.5 & 0.44 \\
\hline Sum & 1.5 & 2.5 & 2.5 & 5.5 & 5.0 & 5.0 & 3.0 & 3.0 & 2.0 & 5.0 & 4.0 & 2.5 & 5.0 & 4.5 & 3.5 & 54.5 & Total \\
\hline 0. V. & 2.8 & 4.6 & 4.6 & $10.1^{*}$ & 9.2 & 9.2 & 5.5 & 5.5 & 3.7 & 9.2 & 7.3 & 4.6 & 9.2 & 8.3 & 6.4 & 90 & 100 \\
\hline
\end{tabular}

In Table 6, The optimum weight $=$ Total weight*100/54.5(\%) and A4 in I2 is 10.1 as the optimum indicator. The weight for $\mathrm{O} 1$ is $18 \%, \mathrm{O} 2$ is $38 \%$ and $\mathrm{O} 3$ is $44 \%$ as well as the weights by AHP method.

Table 7. Ranking result by Normalization

\begin{tabular}{|l|l|l|l|l|l|l|l|l|l|l|l|l|l|l|l|l|l|}
\hline O1 & 0.00 & 0.05 & 0.05 & 0.15 & 0.10 & 0.10 & 0.05 & 0.05 & 0.00 & 0.10 & 0.10 & 0.05 & 0.10 & 0.05 & 0.05 & 1.00 & 18 \\
\hline O2 & 0.02 & 0.05 & 0.05 & 0.10 & 0.10 & 0.10 & 0.05 & 0.05 & 0.02 & 0.10 & 0.07 & 0.05 & 0.10 & 0.10 & 0.07 & 1.00 & 38 \\
\hline O3 & 0.04 & 0.04 & 0.04 & 0.09 & 0.09 & 0.09 & 0.06 & 0.06 & 0.06 & 0.09 & 0.06 & 0.04 & 0.09 & 0.09 & 0.06 & 1.00 & 44 \\
\hline Sam & 0.07 & 0.14 & 0.14 & 0.33 & 0.28 & 0.28 & 0.16 & 0.16 & 0.09 & 0.28 & 0.24 & 0.14 & 0.28 & 0.23 & 0.19 & 3.00 & 100 \\
\hline
\end{tabular}

In Table 7, we estimated the final percentage weights of the output dimensions and also the final normalized weights of input indicators, to the sum of the criteria as innovation outcomes the total weights of the indicators equaled one.

\section{Discussion}

The total results of the correlational analysis show that the weight of affection of the main dimensions in both fuzzy methods of DEA and AHP are the same and the weight of input indicators should be flexible enough because some regional differences and relatives regard to regional economic benefits. All the studies hereby as a knowledge-based discussion have been presented:

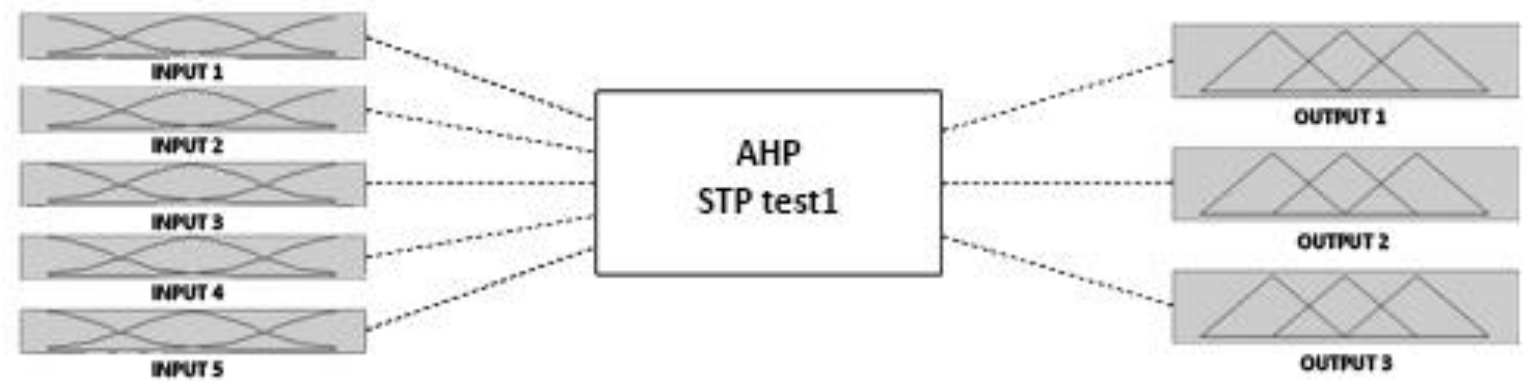

Figure 1. AHP method for innovation inputs

Regardless the traditional STPs measuring systems, in MATLAB structured model as Fig 1., the main dimensions categorized the innovation process by input and output according to the GII scopes with eco-system main goals. The effective dimension in innovation inputs is the Human resources (I2) and in the outputs is the eco-innovation development (O3) with the highest impact for competitive advantage. The analysis also results that the Institutions and Policies (I1) is in the less affection, however some interviewees in Beijing mentioned that in innovation input, the policy is more important. It shows that how much the weights of the index should be flexible in every environment. One unanticipated finding that some experts mentioned is the "eco-innovation diffusion" that should add to the indicator in the further studies (after totally the goal of eco-innovation will achieve). 


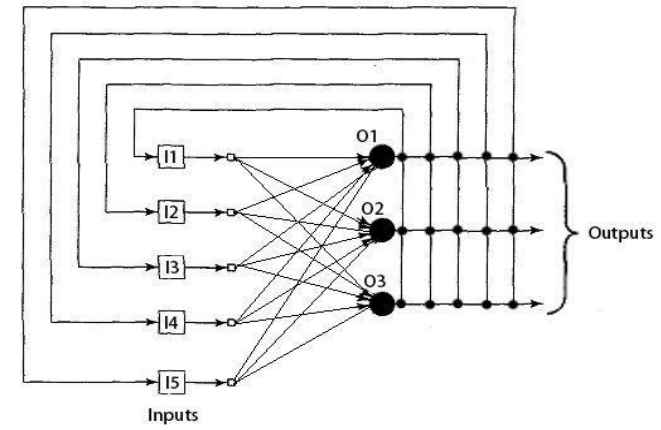

Figure 2. All the outputs in one layer

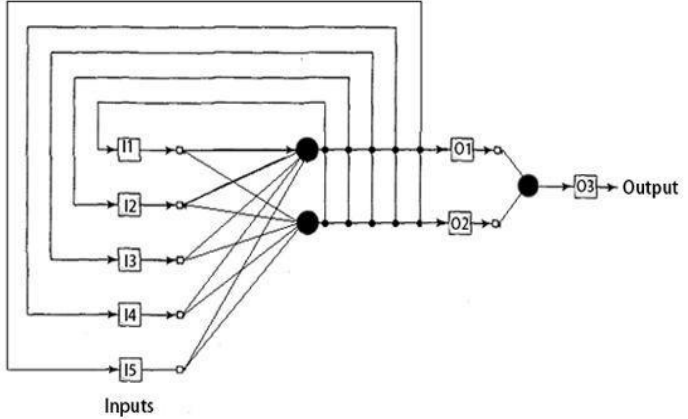

Figure 3. The outputs in two layers

Regarding interviews, the initial structure of the regional Innovation System from inside-out to outside-in is characterized by cooperative innovation as Fig.2(Shukla, Gupta, Dubey, \& Thakur, 2016) but with respect to the experts view, a new approach for the STPs model should be able from inside-out to outside-in with two layers in output that eco-innovation will be the result of the two another outcome dimensions as Fig.3.

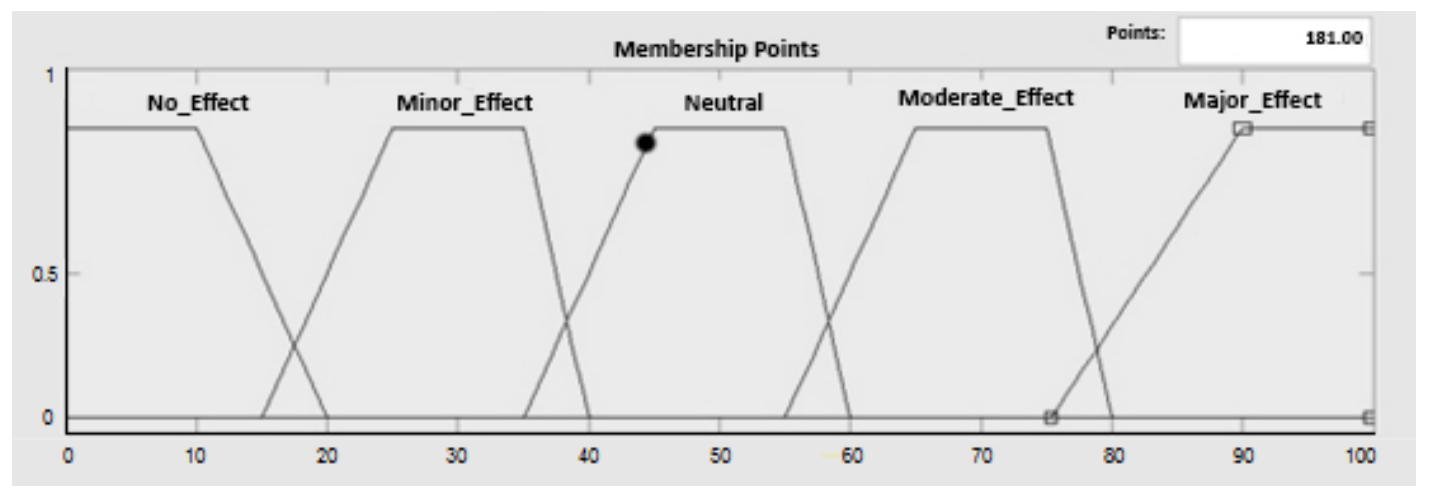

Figure 4. The most important indicator by MATLAB Result

According to Figure 4, the most effective indicator in innovation inputs is "Education" (I4) with the optimum weight of 10.1, in MATLAB, the conclusion of weights (between max 1 and the min 0 ) and outcome variables issued by percentage to decide easier.

Table 8 . The factors of indicators

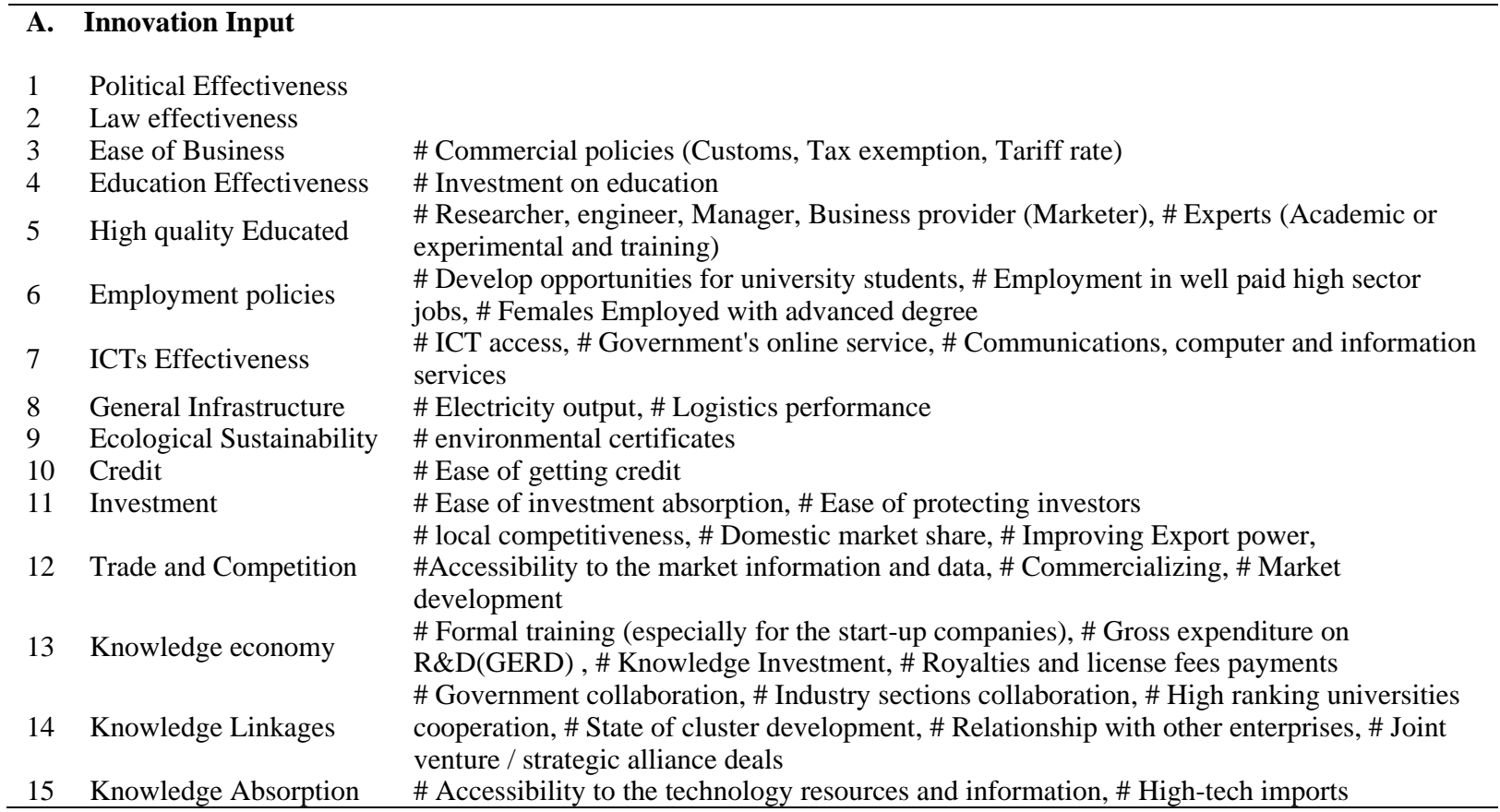




\section{B. innovation outputs}

16 Knowledge Creation

17 Knowledge Impact

18 Knowledge Diffusion

19 Intangible Assets

20 Creation

21 Online Creation

22 Eco-Environment

23 Eco - social process

24 Eco - technological term

\#Patenting and licensing activities, \#Scientific and technical publications, \#Total computer software spending, \#High-tech and medium-high-tech output

\#Growth rate of GDP per person engaged, \#New business density, \#Quality certificates \#High-tech exports, \#Foreign direct investment net outflows, \#R\&D, Technology and knowledge transferring

\#Trademark and branding, \#Business and organizational models creation

\#Cultural and creative goods exports, \#Cultural and creative services exports, \#Global entertainment and media output

\#Generic top-level domains (gTLDs), \#Dynamic Website monthly edits

\# Innovation economy (Capital, investment and financial supports), \# Investment for innovative ideas, \# Internationalization (innovation that compete internationally),

\#Innovation opportunities realized in firms, \# Innovation Policy (Small business development through incubators), \#Modification the SPT Operational management team \# Culture of Innovation (Awareness of innovation beneficial effects), \# The social benefits, \# Sustainable job creation

\# knowledge economic development, \# Numbers of (Technological - based)company start-ups

In Table 8, the main factors that the experts concentrated as the different forms of linkage activities and implications of relevant evidence and the scope for promotional policies. They insist the main benefit of eco-innovation is the social advantages for the located hi-tech enterprises. In addition, we discovered that "Caohejing Hi-Tech Park" has the transportation problem due to located inside the Shanghai (not in the suburb).
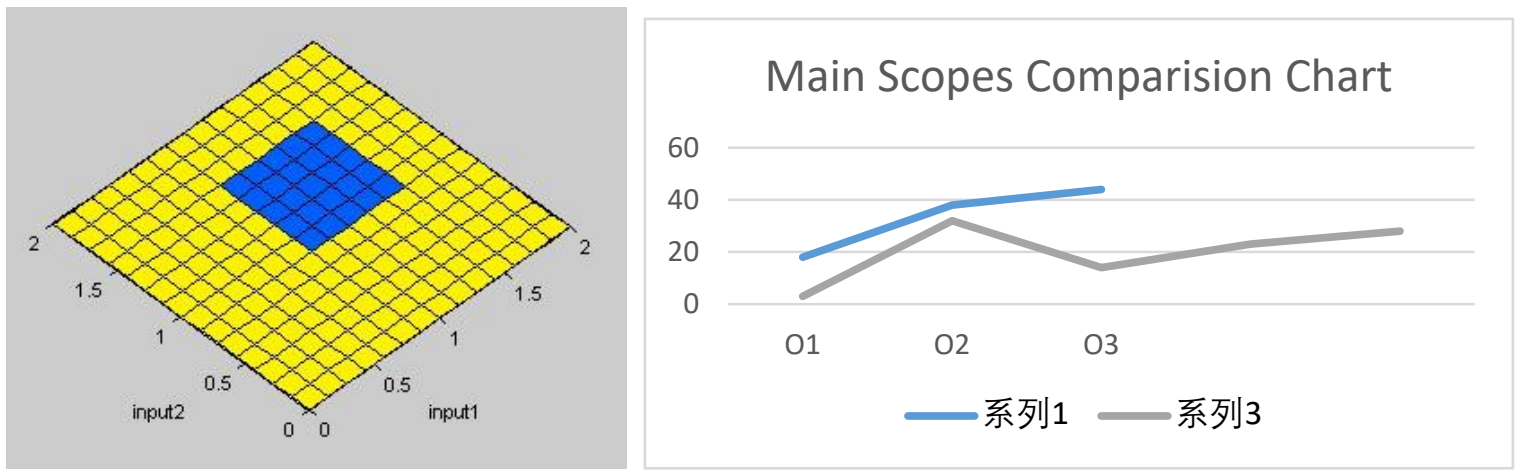

Figure 5. The MATLAB Result of achieving of the goal in Caohejing Hi-Tech Park

The results in Figure 5 shows all pairwise matrix and results present that "Caohejing Hi-Tech Park" has a good score with a significant impact on innovation development and effective value toward eco-system. Finally all of our studies and interviews confirmed by experts and interviewees that the main further competitive advantage in STPs is the ability and capacity of creating innovation by "eco-innovations diffusion". The high-tech clusters in regional economies are presenting an obstacle of realistic assessments of policy and performances relevance.

\section{Conclusion}

Concluding, the new goal of the STPs is to develop the innovation process to a proper eco-innovative system by a novel analytical approach. The hypothesis of this study was undertaken to design a multi-criterion reference framework to measure the effectiveness of the key indicators to achieve the eco-STP system. According to relevant surveys and literature, we associated main key dimensions that are assessed by comparison of different scales and one of the more significant emerges from this study is a new method that has been adopted the traditional scorecards with GII scopes and has established to add the eco-innovation development as a final key.

Overall, the current study is based on a small sample by analyzing an STP in Shanghai and we tried to provide a functions-based operational System by fuzzy methods (AHP and DEA) and finally, we are witnessing that the eco-innovation system is the base of STP competitive advantage evaluation. This study strengthens to separate the innovation process by input and output and also to make a strong comparison link between them by fuzzy evaluation of their affection.

In summary, the top-three dimensions of STPs based on the regional innovation outcome are "Knowledge and technology outputs", "Creative outputs" and "Eco-Innovation Development" and the main input indicators that are influencing the effectiveness are the "education" in "Human resources" dimension, "Investment" in "Market" dimension and also the "Knowledge linkage" in "Knowledge" dimension. 
The final conclusion as the general overview of the literature associated some interesting results that the main benefit of an eco-STP system is to ecological ideas and Culture of Innovation, the stable social benefits (job creation), internationalization, industry cluster effect and finally to share the strong knowledge-based economy and latest technologies (eco-innovation diffusion). It was also understanding that the eco-innovation as a new competitive advantage for the located hi-tech enterprises is effective.

Future research should concentrate on the investigation of "diffusion of eco-innovations" that actually corresponds to the next research paths.

\section{References}

Aliahmadi, A., Sadeghi, M. E., Nozari, H., Jafari-Eskandari, M., \& Najafi, S. E. (2015). Studying Key Factors to Creating Competitive Advantage in Science Park. Paper presented at the Proceedings of the Ninth International Conference on Management Science and Engineering Management. https://doi.org/10.1007/978-3-662-47241-5_82

Alvarez, M. L. (2014). Setting up, Managing and Evaluating EURO Scienceand Technology Parks. European Union: European Commission, Directorate-General for Regional and Urban policy.

Avermaete, T., Morgan, E. J., Viaene, J., Pitts, E., Crawford, N., \& Mahon, D. (2003). Regional patterns of innovation: case study of small food firms. Paper presented at the DRUID summer conference.

caohejing-Park. (n.d.). Retrieved from http://www.caohejing.com/en/index.php

Chang, H. C., Tsai, C. L., \& Henderson, S. (2012). How industrial clusters and regional innovation systems impact the knowledge innovation within the Taiwanese science-based parks firms? New Research on Knowledge Management Applications and Lesson Learned, InTech, Rijeka, 1-24.

Chen, H. H., Chen, S. L., \& Lan, Y. (2016). Attaining a sustainable competitive advantage in the smart grid industry of China using suitable open innovation intermediaries. Renewable \& Sustainable Energy Reviews, 62, 1083-1091. https://doi.org/10.1016/j.rser.2016.03.008

Chun, D., Chung, Y., \& Bang, S. (2015). Impact of firm size and industry type on R\&D efficiency throughout innovation and commercialisation stages: evidence from Korean manufacturing firms. Technology Analysis \& Strategic Management, 27(8), 895-909. https://doi.org/10.1080/09537325.2015.1024645

Clark, J. J. (2014). Siting 'Scientific Spaces' in the US: The Push and Pull of Regional Development Strategies and National Innovation Policies. Environment and Planning C: Government and Policy, 32(5), 880-895. https://doi.org/10.1068/c1271r

Corsaro, D., Ramos, C., Henneberg, S. C., \& Naudé, P. (2012). The impact of network configurations on value constellations in business markets-The case of an innovation network. Industrial Marketing Management, 4l(1), 54-67. https://doi.org/10.1016/j.indmarman.2011.11.017

Díez-Vial, I., \& Fernández-Olmos, M. (2015). Knowledge spillovers in science and technology parks: how can firms benefit most? The Journal of Technology Transfer, 40(1), 70-84. https://doi.org/10.1007/s10961-013-9329-4

Diez-Vial, I., \& Montoro-Sanchez, A. (2016). How knowledge links with universities may foster innovation: The case of a science park. Technovation, 50-51, 41-52. https://doi.org/10.1016/j.technovation.2015.09.001

Donate, M. J., \& Guadamillas, F. (2015). An empirical study on the relationships between knowledge management, knowledge-oriented human resource practices and innovation. Knowledge Management Research \& Practice, 13(2), 134-148. https://doi.org/10.1057/kmrp.2013.36

Drawoska, J. (2011). Measuring the success of science parks: performance, monitoring and evaluation. Recuperado en (2013, Septiembre 10), 20.

Ferrara, M., Lamperti, F., \& Mavilia, R. (2016). Looking for best performers: a pilot study towards the evaluation of science parks. Scientometrics, 106(2), 717-750. https://doi.org/10.1007/s11192-015-1804-2

Formica, P. (2009). Science and Technology Parks (STP): The Evolution.

Gamal, D., Salah, T., \& Elrayyes, N. (2011). How to measure organization Innovativeness. Technology Innovation and Entrepreneurship Center.

GII. (2015). Global Innovation Index. Retrieved on. Retrieved from www.globalinnovationindex.org/

Herrera, M. E. B. (2015). Creating competitive advantage by institutionalizing corporate social innovation. Journal of Business Research, 68(7), 1468-1474. https://doi.org/10.1016/j.jbusres.2015.01.036 
Hu, A. G. Z. (2007). Technology parks and regional economic growth in China. Research policy, 36(1), 76-87. https://doi.org/10.1016/j.respol.2006.08.003

IASP. (n.d., 2016). The role of STPs and areas of innovation. Retrieved from www.iasp.ws/the-role-of-stps-and-innovation-areas

Jiang, H.-J. (2015). Performance evaluation of innovation network-based cross-regional innovative cooperation. Paper presented at the Machine Learning and Cybernetics (ICMLC), 2015 International Conference on.

Jongwanich, J., Kohpaiboon, A., \& Yang, C.-H. (2014). Science park, triple helix, and regional innovative capacity: province-level evidence from China. Journal of the Asia Pacific Economy, 19(2), 333-352. https://doi.org/10.1080/13547860.2014.880285

Jordan, A., \& Huitema, D. (2014). Innovations in climate policy: the politics of invention, diffusion, and evaluation. Environmental Politics, 23(5), 715-734. https://doi.org/10.1080/09644016.2014.923614

Karakaya, E., Hidalgo, A., \& Nuur, C. (2014). Diffusion of eco-innovations: A review. Renewable and Sustainable Energy Reviews, 33, 392-399. https://doi.org/10.1016/j.rser.2014.01.083

Kbar, G., \& Aly, S. (2015). Goal-based Key Performance Indicators of Science Parks' Effectiveness: A Case Study at Riyadh Techno-Valley. British Journal of Economics, Management \& Trade, 8(3), 237-257.

Kolahi, J. (2015). Dental science and technology parks: Rethinking university-industry connections. Dental Hypotheses, 6(2), 40. https://doi.org/10.4103/2155-8213.158467

Li, X., Qin, X., Jiang, K., Zhang, S., \& Gao, F. Y. (2015). Human Resource Practices and Firm Performance in China: The Moderating Roles of Regional Human Capital Quality and Firm Innovation Strategy. Management and Organization Review, 11(02), 237-261. https://doi.org/10.1017/mor.2015.12

Liberati, D., Marinucci, M., \& Tanzi, G. M. (2015). Science and Technology Parks in Italy: main features and analysis of their effects on the firms hosted. The Journal of Technology Transfer, 1-36.

Liu, N., \& Guan, J. (2016). Policy and innovation: Nanoenergy technology in the USA and China. Energy Policy, 91, 220-232. https://doi.org/10.1016/j.enpol.2016.01.020

Löfsten, H., \& Lindelöf, P. (2002). Science Parks and the growth of new technology-based firms-academic-industry links, innovation and markets. Research policy, 31(6), 859-876. https://doi.org/10.1016/S0048-7333(01)00153-6

Mahroum, S., \& Alsaleh, Y. (2012). Measuring innovation efficacy: an operational framework for mapping and measuring innovation capacity and performance of countries.

Manrique, J. A., \& Velásquez, J. R. (2011). Innovation indices of the Colombian industrial groups from two national innovation surveys. Paper presented at the 2011 Proceedings of PICMET'11: Technology Management in the Energy Smart World (PICMET).

Martinsuo, M., \& Poskela, J. (2011). Use of evaluation criteria and innovation performance in the front end of innovation. Journal of Product Innovation Management, 28(6), 896-914. https://doi.org/10.1111/j.1540-5885.2011.00844.x

Minguillo, D., \& Thelwall, M. (2015). Which are the best innovation support infrastructures for universities? Evidence from R\&D output and commercial activities. Scientometrics, 102(1), 1057-1081. https://doi.org/10.1007/s11192-014-1458-5

Minguillo, D., Tijssen, R., \& Thelwall, M. (2015). Do science parks promote research and technology? A scientometric analysis of the UK. Scientometrics, 102(1), 701-725.

https://doi.org/10.1007/s11192-014-1435-z

Nishitani, K., \& Itoh, M. (2016). Product innovation in response to environmental standards and competitive advantage: a hedonic analysis of refrigerators in the Japanese retail market. Journal of Cleaner Production, 113, 873-883. https://doi.org/10.1016/j.jclepro.2015.11.032

Perrin, B. (2002). How to-and how not to-evaluate innovation. Evaluation, 8(1), 13-28. https://doi.org/10.1177/1358902002008001514

Podinovski, V. V. (2016). Optimal weights in DEA models with weight restrictions. European Journal of Operational Research, 254(3), 916-924. https://doi.org/10.1016/j.ejor.2016.04.035

Ruiz-Ortega, M. J., Parra-Requena, G., \& Garcia-Villaverde, P. M. (2016). Do Territorial Agglomerations Still Provide Competitive Advantages? A Study of Social Capital, Innovation, and Knowledge. International 
Regional Science Review, 39(3), 259-290. https://doi.org/10.1177/0160017613512652

Rycroft, R. W. (2007). Does cooperation absorb complexity? Innovation networks and the speed and spread of complex technological innovation. Technological Forecasting and Social Change, 74(5), 565-578. https://doi.org/10.1016/j.techfore.2006.10.005

Sadeghi, M. E., \& Sadabadi, A. A. (2015). Evaluating Science Parks Capacity to Create Competitive Advantages: Comparison of Pardis Technology Park and Sheikh Bahaei Science and Technology Park in Iran. International Journal of Innovation and Technology Management, 12(06), 1550031. https://doi.org/10.1142/S0219877015500315

Shukla, D. P., Gupta, S., Dubey, C. S., \& Thakur, M. (2016). Geo-spatial Technology for Landslide Hazard Zonation and Prediction.

Sohn, S. Y., Kim, D. H., \& Jeon, S. Y. (2016). Re-evaluation of global innovation index based on a structural equation model. Technology Analysis \& Strategic Management, 28(4), 492-505. https://doi.org/10.1080/09537325.2015.1104412

Specht, K., Zoll, F., \& Siebert, R. (2016). Application and evaluation of a participatory "open innovation" approach (ROIR): The case of introducing zero-acreage farming in Berlin. Landscape and Urban Planning, 151, 45-54. https://doi.org/10.1016/j.landurbplan.2016.03.003

Sreedevi, R., Vimala, V., Rameswari, P., Sateesh, S., \& Professor, A. P. (2016). An Application of Fuzzy logic and DEA in Agriculture Sector. International Journal of Engineering Science, 4876.

Stosic, B., Milutinovic, R., Zakic, N., \& Zivkovic, N. (2016). Selected indicators for evaluation of eco-innovation projects. Innovation: The European Journal of Social Science Research, 1-15. https://doi.org/10.1080/13511610.2016.1157682

Tsai, C.-L., \& Chang, H.-C. (2016). Evaluation of critical factors for the regional innovation system within the HsinChu science-based park. Kybernetes, 45(4), 699-716. https://doi.org/10.1108/K-02-2015-0059

Vasquez-Urriago, A. R., Barge-Gil, A., \& Rico, A. M. (2016a). Science and Technology Parks and cooperation for innovation: Empirical evidence from Spain. Research policy, 45(1), 137-147. https://doi.org/10.1016/j.respol.2015.07.006

Vasquez-Urriago, A. R., Barge-Gil, A., \& Rico, A. M. (2016b). Which firms benefit more from being located in a Science and Technology Park? Empirical evidence for Spain. Research Evaluation, 25(1), 107-117. https://doi.org/10.1093/reseval/rvv033

Wikipedia. (n.d.-a, 28,7,2016). Eco-innovation. Retrieved from https://en.wikipedia.org/wiki/Eco-innovation

Wikipedia. (n.d.-b, 23,8,2016). Science Park. Retrieved from https://en.wikipedia.org/wiki/Science_park

Wikipedia. (n.d.-c, 18,9,2016). Shanghai. Retrieved from https://en.wikipedia.org/wiki/Shanghai

Wikipedia. (n.d.-d, 6,9,2016). Zhangjiang Hi-Tech Park. Wikipedia. Retrieved from https://en.wikipedia.org/wiki/Zhangjiang_Hi-Tech_Park

WIPO. (2015). Global Innovation Index 2015: Switzerland, UK, Sweden, Netherlands, USA are Leaders. The World Intellectual Property Organization.

Wright, M., Liu, X., Buck, T., \& Filatotchev, I. (2008). Returnee Entrepreneurs, Science Park Location Choice and Performance: An Analysis of High - Technology SMEs in China. Entrepreneurship Theory and Practice, 32(1), 131-155. https://doi.org/10.1111/j.1540-6520.2007.00219.x

Wu, J., Wang, C., Hong, J., Piperopoulos, P., \& Zhuo, S. (2016). Internationalization and innovation performance of emerging market enterprises: The role of host-country institutional development. Journal of World Business, 51(2), 251-263. https://doi.org/10.1016/j.jwb.2015.09.002

Xu, Y.-1., Wang, Q., \& Wang, W. (2011). Fuyang paper industrial cluster performance evaluation based on fuzzy evaluation. Paper presented at the 2011 International Conference on Electronics, Communications and Control (ICECC). https://doi.org/10.1109/ICECC.2011.6068142

Yang, J., \& Ying, L. M. (2015). A Study on the Effects of Knowledge Management on Innovation Strategies And Competitive Advantages. Acta Oeconomica, 65, 159-171. https://doi.org/10.1556/032.65.2015.S2.12

Yim, D., Cho, H. H., \& Kim, E. (2015). Revisit the concept and usefulness of Science and Technology Park and implication for the regional innovation policy: Cases of Seoul and Gyeonggi Province in Korea. Paper presented at the 2015 Portland International Conference on Management of Engineering and Technology 
(PICMET).

Zeng, S. X., Xie, X. M., \& Tam, C. (2010). Evaluating Innovation Capabilities For Science Parks: A SYSTEM MODEL. Technological and Economic Development of Economy, 16(3), 397-413. https://doi.org/10.3846/tede.2010.25

Zhang, H., \& Sonobe, T. (2011). Development of science and technology parks in China, 1988-2008. Economics: The Open-Access, Open-Assessment E-Journal, 5, 6.

Zou, Y., \& Zhao, W. (2014). Anatomy of Tsinghua University Science Park in China: institutional evolution and assessment. The Journal of Technology Transfer, 39(5), 663-674.

https://doi.org/10.1007/s10961-013-9314-y

\section{Notes}

Note 1. European Commission (2017). Eco-innovation [online]. Available at: https://ec.europa.eu/environment/ecoap/indicators/index_en

Note 2. Bloomberg Innovation Index, Bogota Manual Index, Oslo Manual Index, Florida Creative Class Index, Global Competitiveness Report, Information Technology and Innovation Foundation (ITIF) Index, Innovation Capacity Index (ICI), Indiana Innovation Index, Innovation Union Scoreboard, Innovations Indikator, INSEAD Innovation Efficacy Index, International Innovation Index, National Association of Manufacturers (NAM), Management Innovation Index, New York City Economic Development Corporation Innovation Index (NYCEDC), State Technology and Science Index, World Competitiveness Scoreboard.

\section{Copyrights}

Copyright for this article is retained by the author(s), with first publication rights granted to the journal.

This is an open-access article distributed under the terms and conditions of the Creative Commons Attribution license (http://creativecommons.org/licenses/by/4.0/). 